\title{
Investigation of the Barents Sea Upper Layer Response to the Polar Low in 1975
}

\author{
N. A. Diansky ${ }^{1,2,3}$, I. I. Panasenkova, *, V. V. Fomin ${ }^{2,4}$ \\ ${ }^{1}$ Lomonosov Moscow State University, Moscow, Russian Federation \\ ${ }^{2}$ Marchuk Institute of Numerical Mathematics, Russian Academy of Sciences, Moscow, Russian Federation \\ ${ }^{3}$ Marine Hydrophysical Institute of RAS, Sevastopol, Russian Federation \\ ${ }^{4}$ Zubov State Oceanographic Institute, Moscow, Russian Federation \\ *ipanasenkova@mail.ru
}

Purpose. The present paper is focused on reproducing the extreme polar low observed over the Barents Sea in early January 1975, on the metocean hindcast data and on analyzing the upper sea layer response to the cyclone passage.

Methods and Results. All the calculations are carried out based on the Marine and Atmospheric Research System for simulating hydrometeorological characteristics of the western seas in the Russian Arctic (the Barents, White, Pechora and Kara seas). The main components of this system are the regional non-hydrostatic model of atmospheric circulation WRF (spatial resolution is $15 \mathrm{~km}$ ) and the physically complete three-dimensional $\sigma$-model of marine circulation INMOM (spatial resolution is $2.7 \mathrm{~km}$ ). The atmospheric reanalysis data and the results of previous studies are used. The polar low produced a severe impact on the central and eastern parts of the Barents Sea, namely, being strongly influenced by the storm winds, the near-surface current velocities changed significantly. During a storm period in these parts of the Barents Sea, the drift component prevails over the tidal one. The tidal component prevails in the shallow southern part of the Barents Sea even during the most extreme storm period. It is shown that a polar low can lead to increase of the sea surface temperature in the Barents Sea by more than $1^{\circ} \mathrm{C}$.

Conclusion. The sea surface temperature positive anomaly is formed by the dynamic processes associated with vertical mixing, upwelling in the western and central parts of the Barents Sea, the Ekman drift and downwelling near the Novaya Zemlya coast. Contribution of the sea-atmosphere heat exchange to formation of the surface temperature positive anomalies is negligible. On the contrary, in the southern part of the Barents Sea and in the Pechora Sea, a significant surface temperature decrease (by almost $1.5^{\circ} \mathrm{C}$ ) is observed during a polar low passing. This is a result of the sea upper layer cooling due to the heat transfer from the sea surface to the atmosphere.

Keywords: Arctic seas, extreme storm, ocean circulation, sea surface temperature anomaly.

Acknowledgements: The authors are grateful to S.K. Gulev, V.V. Ivanov, G.K. Korotaev for their valuable comments while preparing the paper. The work was supported by the Russian Science Foundation (grant No 17-77-30001).

For citation: Diansky, N.A., Panasenkova, I.I. and Fomin, V.V., 2019. Investigation of the Barents Sea Upper Layer Response to the Polar Low in 1975. Physical Oceanography, [e-journal] 26(6), pp. 467-483. doi:10.22449/1573-160X-2019-6-467-483

DOI: 10.22449/1573-160X-2019-6-467-483

(C) 2019, N.A. Diansky, I.I. Panasenkova, V.V. Fomin

(C) 2019, Physical Oceanography

\section{Introduction}

High latitude seas investigation is not possible without using numerical modeling modern techniques due to the inaccessibility and severe climatic conditions of the Arctic basin. This is especially relevant for studying the sea upper layer response to the passage of the intense polar lows (PLs), regularly observed in the Barents Sea [1, 2]. Horizontal scale of the PL is approximately 150-600 km, and a steady wind at $10 \mathrm{~m}$ altitude exceeds $13.8 \mathrm{~m} / \mathrm{s}$ - the force of the storm is 
more than 7 points according to the Beaufort scale [2]. The maximum wind speeds in the PL often exceed $22 \mathrm{~m} / \mathrm{s}$. In [3] the most intense cyclones are considered those the pressure in the center of which is less than $985 \mathrm{hPa}$. Polar lows are a winter phenomenon that occurs mainly from October to April, since the difference between the temperature of air and open water is the largest during this period, which is a necessary condition for the formation of PL. According to [4], the PL is considered mesoscale if its size is less than $2000 \mathrm{~km}$.

There is a large number of works studying the reaction of the ocean to the passage of intense tropical and quasi-tropical cyclones, for example, in the Gulf of Mexico [5, 6], in the South China Sea [7], in the Pacific Ocean [8-10], in the Bay of Bengal [11] and even in the Black Sea [12]. There are much less similar works for high-latitude seas, where intense, but already PL, are also observed. The works $[13,14]$ can be noted.

Currently, there is no answer to the question about PL formation frequency variation due to the rapid warming of the Arctic [15-17]. On the one hand, this warming, as shown in [3], leads to an increase in the frequency of formation of powerful PLs. At the same time, it is shown in [18] that there is no trend in the PL formation frequency, based on the reanalysis data of the National Centers for Environmental Prediction/National Center for Atmospheric Research (NCEP/NCAR) for the period 1948-2005. In [19] in accordance to the analysis of future climate changes in $21^{\text {st }}$ century a significant decrease in the appearance of PLs is expected as a result of sea ice area reduction and a gradual displacement of the ice edge to the north, which is one of the conditions for the formation of PLs.

The response in the hydrodynamic and wind-wave characteristics of the Barents Sea to the intensive PL passage on January 1-4, 1975 was studied in our work [20], using the numerical modelling methods. This storm was the strongest for the central and eastern parts of the Barents Sea from 1950s until the early 1980s, according to the database [21]. In accordance with this data, the recurrence interval of such a storm is estimated at about 400 years. The PL intensity was also facilitated by the fact that in 1975 a minimum of the Atlantic multidecadal oscillation and a related decrease in the temperature in the Northern Hemisphere were observed [22]. The latter could lead to a background increase in the difference between the surface temperature of air and open water in the Arctic basin, which, in turn, could contribute to the PL intensification.

In this paper, in contrast to [20], the thermal response in marine dynamics to the storm passage at the beginning of 1975 was analyzed and the reaction of the upper mixed layer (UML) of the Barents Sea was evaluated. In this study, as in [20], to reproduce the extreme storm characteristics of the beginning of 1975 the Marine and Atmospheric Research System (MARS) for the hydrometeorological characteristics of the West Arctic seas of Russia is used. This system is implemented at SOI (N. N. Zubov State Oceanographic Institute).

At present, there are domestic and foreign systems for operational analysis and forecast for the Barents Sea hydrophysical characteristics. Software package for short-term forecast of the White and Barents Sea level and currents, taking into account the ice cover [23], is implemented and used in the operational mode in the Hydrometeorological Center of the Russian Federation. It is based on a threedimensional hydrodynamic model of marine circulation with a spatial resolution 
of 5 nautical miles [24], atmospheric forcing for which is calculated using the Consortium for Small-scale Modeling-Russia (COSMO-ru) model [25]. However, only the current velocities and sea level serve as prognostic variables of this model, and temperature and salinity are set according to the climatic observational data.

System for the operational modeling of the sea level and currents forecast for the Arctic Ocean and its seas [26] was developed at the Arctic and Antarctic Research Institute (AARI). This system is based on the AARI-IOCM marine circulation model with a spatial resolution of $13.8 \mathrm{~km}$ [27]. In 2012 it was recommended by the Central Methodological Commission of Roshydromet for the use in the operational work of the AARI.

Towards an Operational Prediction System for the North Atlantic European Coastal Zones (TOPAZ4), developed by the Nansen Environmental and Remote Sensing Center (NERSC), is used for the operational forecast and metocean hindcast data analysis of the Arctic basin and the North Atlantic Ocean [28]. The TOPAZ4 system is based on the Hybrid Coordinate Ocean Model (HYCOM) version 2.2, the spatial resolution of which varies in the range of $12-16 \mathrm{~km}$. To set the atmospheric effect the European Center for Medium-Range Weather Forecasts (ECMWF) atmospheric forcing is used. The data assimilation method in the TOPAZ4 system is implemented based on the Kalman ensemble filter (EnKF).

To solve the problem of a comprehensive study of the marine response to the PL passage, all of the above systems are not suitable mainly due to the rough spatial resolution of the marine models used in them. The MARS is a complex of numerical models and it consists of a regional non-hydrostatic atmospheric circulation model - Weather Research Forecast Model (WRF) [29] with a spatial resolution of $15 \mathrm{~km}$ for calculating meteorological parameters, of threedimensional $\sigma$-model of the Institute of Numerical Mathematics Ocean Model (INMOM) sea circulation and sea ice [30-32] in the version for the Barents, White, Pechora and Kara Seas with a spatial resolution of $2.7 \mathrm{~km}$ [20] for calculating hydrological parameters and ice characteristics, of Russian atmospheric-wave model (RAVM) [33] with spatial resolution as in the atmospheric model for calculating wind-wave characteristics. Non-hydrostatic atmospheric circulation model WRF with the used spatial resolution can reproduce mesoscale atmospheric processes, such as, for example, the Novaya Zemlya bora formation [34]. Using the atmospheric WRF model 2-m air temperature and relative humidity, 10-m wind speed, incident short-wave and long-wave radiation, precipitation, and pressure at sea level were calculated with hourly output. All these atmospheric parameters are used in the INMOM marine circulation model to calculate heat, fresh water, and momentum fluxes on the sea surface. The input data in the RAVM model are only wind speed fields.

Detailed description of the initial version of the MARS is given in [35] and description of the modern modified version of the system is given in [20]. Note that the latest version of the MARS is currently being adapted to be connected to the system of marine forecasts of the World Ocean, the Arctic and Azov and Black Sea basins. These days it is developed as a part of the RSF project No. 17-77-30001, which will permit to use more accurate conditions at the liquid boundaries of the region in the future. 
To solve the stated problem, numerical simulation using MARS was performed since the beginning of October 1974 until the end of January 1975, so that the circulation of the Arctic basin western seas of the Russian part could adjust to the atmospheric forcing calculated by the WRF model. While conducting numerical calculations with the regional WRF model, the open source data of the global reanalysis of NCEP/NCAR (https://rda.ucar.edu/datasets/ds090.0) was used as initial data. Information about the underlying surface was taken from the Moderate Resolution Imaging Spectroradiometer (MODIS) data with a spatial resolution of 30". The monthly average data of the electronic climatic atlas was used [36] to set the initial conditions for temperature and salinity in the marine circulation INMOM model.

Since the atmospheric and marine parts of the MARS are not interactive, the response of the marine circulation to the atmospheric forcing was calculated in the numerical simulation, which is the topic of the present work.

\section{Reproduction of the polar low parameters in 1975 in the Barents Sea, taking into account the ice conditions}

The formation of the studied cyclone began in the northwestern part of the Greenland Sea on December 30, 1974, along the sea ice edge, where the majority of PLs usually nucleate [2, 37]. Advection of cold air from an ice-covered surface onto an ice-free water surface led to the development of strong vertical instability and convection, which are the main reasons for intense PLs genesis $[1,2]$.

This extreme PL with very low pressure in the center, moving at a speed of approximately $7 \mathrm{~m} / \mathrm{s}$, in less than two days reached the northwestern part of the Barents Sea, where it slowed down to $\sim 1 \mathrm{~m} / \mathrm{s}$, stayed over the sea for almost 5 days and became the cause of the storm.

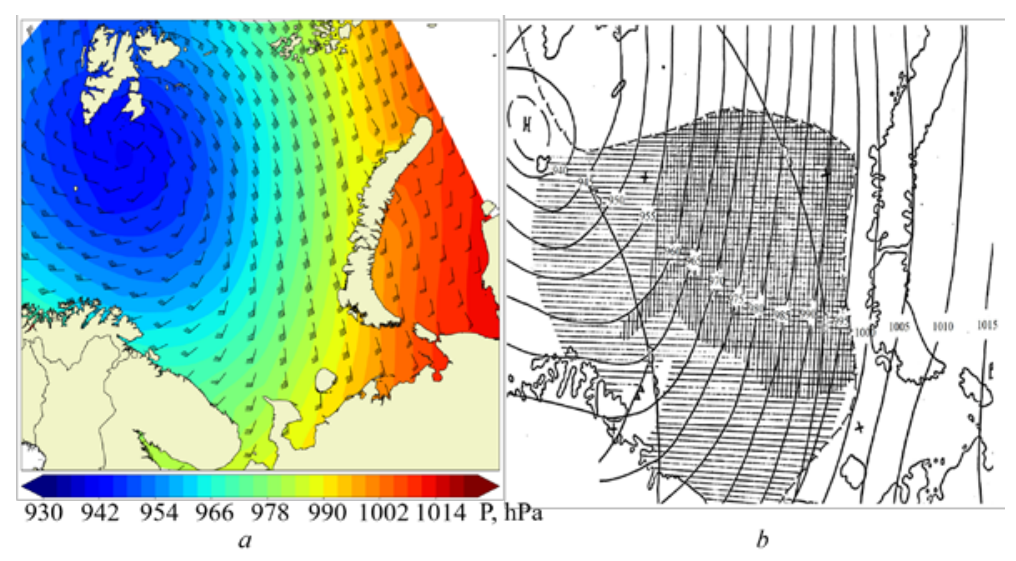

F i g. 1. Synoptic situation in the Barents Sea: $a$ - map of pressure $(P)$ and surface wind speeds $(\mathrm{m} / \mathrm{s}$, represented by wind barbs) on January 3, 1975 at 11:00 a. m. based on the results of the WRF model calculations in the azimuthal projection (half of a barb corresponds to the wind speed $2.5 \mathrm{~m} / \mathrm{s}$, full barb - to the speed $5 \mathrm{~m} / \mathrm{s}$ ); $b$ - according to the Zubov State Oceanographic Institute archive data on January 3, 1975 at 00:00 a. m. [20] (the dashed line represents the floating ice zone; the lattice hatching marks the water area where the wind speeds exceed $25 \mathrm{~m} / \mathrm{s}$; the horizontal hatching the water area where the wind speeds exceed $20 \mathrm{~m} / \mathrm{s}$ ) 
According to the calculation results by the WRF model, the storm reached its maximum intensity on January 3, 1975, around 11:00 a.m.*. The wind speed exceeded $20 \mathrm{~m} / \mathrm{s}$ in the southern and eastern parts of the Barents Sea (Fig. 1, a). The minimum pressure was $941 \mathrm{hPa}$ in the center of the cyclone. Fig. 1b shows the available archival data of the synoptic situation on January 3, 1975 at 00:00 a.m.. Thus, the atmospheric characteristics calculated at the time of the maximum storm intensity are in rather good agreement with the directly observed ones.

\section{Dynamic response of the Barents Sea to the polar low passage in 1975, taking into account ice conditions}

The storm passage for the central and eastern parts of the Barents Sea can be seen in the variation of near-surface current velocity. The structure of the currents in these sea areas was almost completely determined by the drift component (Fig. 2). The development of the response to the storm situation in the current velocity structure shows that already on January 3 the current velocities here are damping. But at the same time, there is an intensification of the branch of the Novaya Zemlya current in the coastal zone of Novaya Zemlya, caused by cyclone winds. The total current velocity increases significantly in the Barents Sea southern part, at the entrance to the White Sea and in the Kola Peninsula, when the drift and tidal currents directions coincide.

There is a rapid change in the location of the ice field edge due to the wind drift and currents impact. Moreover, during this storm a favorable situation is created when water is cleared of ice in the Shtokman field and the ice field is removed from it by $50 \mathrm{~km}$ in 48 hours.

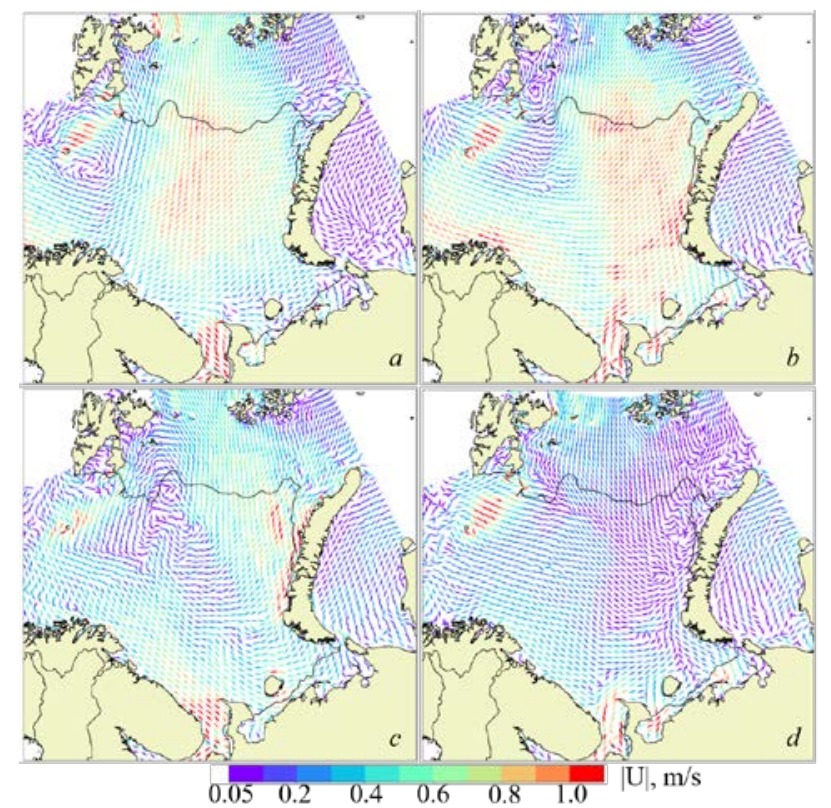

F i g. 2. Total near-surface current velocities (|U|) on January 3, 1975 at 03:00 am. - a, on January 3, 1975 at 11:00 am. $-b$, on January 4, 1975 at 01:00 am. $-c$ based on the results of the INMOM model calculations and the tidal current velocity on January 3, 1975 at 11:00 am. The line on the figures marks the boundary of the 1\%-concentration ice 
It is interesting to analyze the variability of the kinetic energy in the Barents Sea during the passage of an extreme storm. To do this, we studied the density of kinetic energy normalized to water density in the surface 3-meter layer averaged over the entire sea basin, as well as at the locations of the Shtokman gas condensate field and at the Prirazlomnaya offshore ice-resistant fixed platform.

The Barents and White seas are characterized by intense tides. Analysis of the kinetic energy of the total current velocity and only tidal movements showed that during non-extreme winds the contribution of the tidal current velocity to the kinetic energy is more significant with respect to the drift and gradient components of the current velocity. During extreme winds in the whole Barents Sea basin the contribution of the drift component exceeds the contribution of the tidal component to the kinetic energy. For the Shtokman field the drift component contribute the most to the kinetic energy, since it is situated in the region of small tidal movements [24]. The contribution of the tidal component to the kinetic energy prevails near the Prirazlomnaya platform both during storm and non-storm periods, since the tide is especially strong in the southern part of the Barents Sea [24].

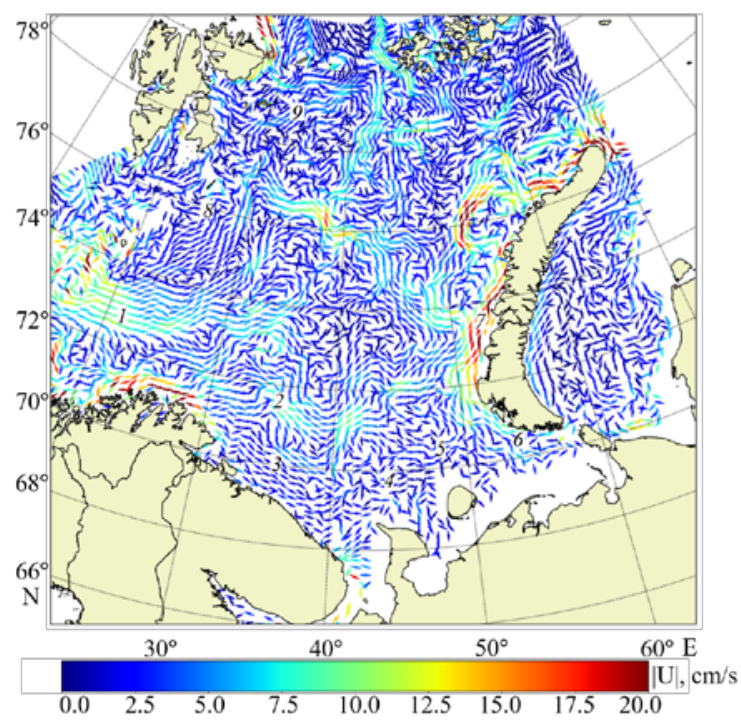

F i g. 3. Current velocity $(|\mathrm{U}|)$ averaged over the storm period (January 1-6, 1975) at the $50 \mathrm{~m}$ depth. The numbers correspond to the standard currents [39]: 1 - North Cape Current, 2 - Murmansk Current, 3 - Coastal Murmansk Current, 4 - Belomorskoe Current, 5 - Kolguevo-Pechora Current, 6 - Litke Current, 7 - Novaya Zemlya Current, 8 - Medvezhinsky Current, 9 - Barents Current

Despite the intense storm effect, which significantly changed the surface structure of the currents, thermohaline currents do not change as much. Figure 3 shows the calculated current velocities at the depth of $50 \mathrm{~m}$ averaged over the period of the storm passage on January 1-6, 1975. These currents are in good agreement with the scheme of climatic currents in the Barents Sea [38]. The calculation results show that, despite the passage of such an intense storm, the speed of subsurface currents varies slightly. At the $50 \mathrm{~m}$ depth, the North Cape, the Murmansk and the Coastal Murmansk Currents clearly stand out [39]. 
In the coastal zone of the Barents and the Pechora seas, the White Sea and the Pechora Currents are traced. Two-way water flow through the Kara Strait is also observed [35], as well as the Litke Current, and the Novaya Zemlya Current [39]. A complex structure is observed in the central part of the Barents Sea, caused by significant variability of the current field, and is hardly determined at such small averaging scales. At the same time, the Medvezhinsky Current, the Barents Current, etc. are observed slightly to the north.

\section{The reaction of the upper layer of the Barents Sea to the polar low passage in 1975}

As already noted, there are a large number of works (for example, [5-7, 12]) where tropical and quasi-tropical cyclones and their impact on the hydrodynamic characteristics of oceans and seas are studied. They show that a negative anomaly of the sea surface temperature (SST) is formed as a result of the intense cyclones passing. SST decrease by several degrees was noted in the Gulf of Mexico in [5], in the South China Sea in [7] and in the Pacific Ocean in [8] after the passing of the powerful cyclones.

One of the reasons for the SST variation are turbulent vertical mixing, caused by the storm wind, and upwelling, induced by the cyclonic wind. There are usually warmer layers of water on the surface compared to the underlying layers. Therefore, both processes facilitate the penetration of colder waters from the thermocline into the UML, which results in its cooling and deepening. It should be noted that vertical mixing occurs in a short period of time, usually in a few hours, and leads to the cooling of the sea surface waters, thereby reducing the turbulent heat flux (latent and sensible) from the ocean to the atmosphere and, therefore, reducing the energy supply to the cyclone. According to the modeling results [40], it was found that $85 \%$ of the SST variation is due to the vertical mixing, and the rest - to advection and heat fluxes between the ocean surface and the atmosphere. Deep waters upwelling also takes place in case of slow cyclone movement in places of divergence under its center, leading to the UML cooling. In turn, this results in the negative feedback, causing decrease in the energy supply from the ocean. Therefore, an increase of the tropical cyclone energy is occurred during its rapid movement, which is usually observed in the real world.

There is a temperature inversion in the upper layer of the Arctic seas, due to the cooling and desalination of the Atlantic waters, coming from the Norwegian Sea, as a result of their interaction with the atmosphere, ice melting and water freezing, vertical convection and fresh water input from the continent [13, 41]. Therefore, in the Arctic seas after the PL passage the same cooling and deepening processes typical for the tropical cyclones should lead to an increase in the UML temperature, rather than a decrease, due to the water exchange with underlying warmer waters. An increase in temperature by $2^{\circ} \mathrm{C}$ in a few hours was shown in [13] as a result of the PL passing at the Lofoten Islands according to the satellite observations. It should be noted that a narrow and intense branch of the warm North Atlantic Current flows under the surface waters here. Thus, positive feedback should be observed for the PL in the Arctic seas, in contrast to the tropical seas, leading to an increase in the energy supply of the cyclone from the ocean. Therefore, an increase in the PL energy is also possible with its relatively slow movement. 
However, it should be noted that the presence of temperature inversion in depth could also lead to an increase in the SST after tropical cyclones passing. This was shown in [11] using the example of a tropical cyclone in the Bay of Bengal, where a vertical temperature inversion was formed in winter.

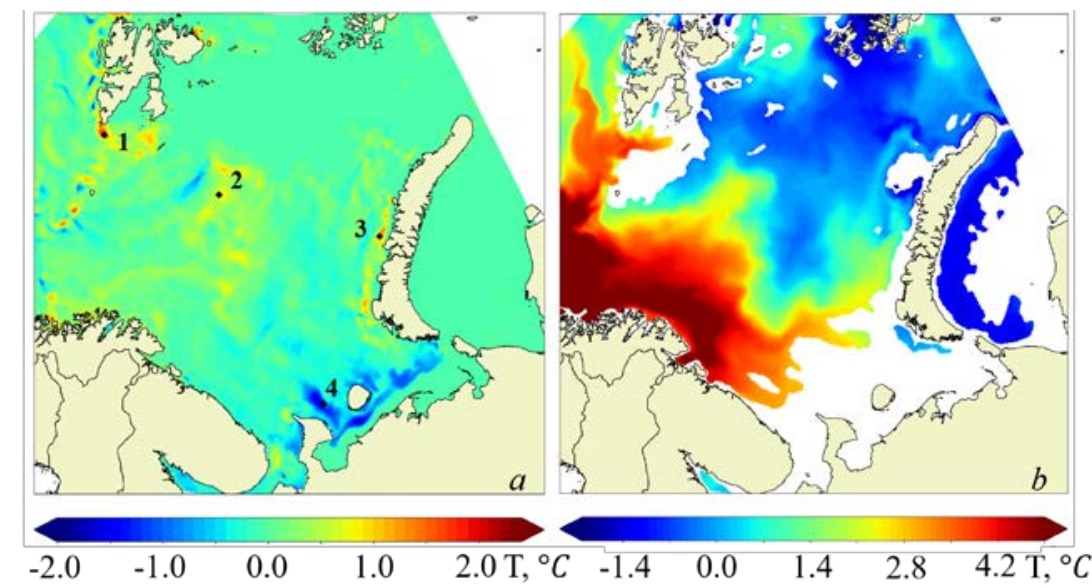

F i g. 4. Sea surface temperature anomaly $\left({ }^{\circ} \mathrm{C}\right)$ during the most extreme storm period (January 3 , 1975 at 00:00 a. m.) based on the results of numerical calculations (the points correspond to the main SST anomalies in the Barents Sea supplied below with the temperature profiles: 1 - near the southern coast of Spitsbergen $\left(76.28^{\circ} \mathrm{N}, 17.46^{\circ} \mathrm{E}\right), 2$ - in the central part of the Barents Sea $\left(75.5^{\circ} \mathrm{N}, 34^{\circ} \mathrm{E}\right)$, 3 - near the Novaya Zemlya western coast $\left(74.1^{\circ} \mathrm{N}, 53.46^{\circ} \mathrm{E}\right), 4-$ in the Pechora Sea $\left(69^{\circ} \mathrm{N}\right.$, $\left.\left.46^{\circ} \mathrm{E}\right)\right)-a$; water temperature averaged for the storm period at the $140 \mathrm{~m}$ depth $-b$

The results of our calculations of the hydrothermodynamic characteristics of the western seas of the Russian Arctic during a storm (early January 1975) support the reasoning given above. At this time the near-surface water warming is reproduced practically throughout the entire Barents Sea. The presence of PLs led to the surface temperature increase by $\sim 1.5^{\circ} \mathrm{C}$ near the southern coast of Svalbard and by almost $1^{\circ} \mathrm{C}$ in the central part of the Barents Sea and on the western coast of Novaya Zemlya (Fig. 4). Fig. 4a shows the anomaly of the calculated SST as the difference between the temperatures at the time of the maximum storm intensity (00:00 03.01.1975) and at the time of the storm beginning (00:00 01.01.1975) in the Barents Sea. The water temperature averaged over the period of the storm at the depth of $140 \mathrm{~m}$ (Fig. 4, b) is in good agreement with the distribution of warm and salty Atlantic waters in the Barents Sea given in [42]. These warm deep waters are a source of positive anomalies that occur during the cyclone passing. The branch of the North Atlantic Current near the coast of Svalbard represents the West Svalbard Current, and Atlantic waters flow into the central part of the Barents Sea along with the northern branch of the North Cape Current.

As for the nature of the warm SST anomalies occurrence (Fig. 4, a), they can be due to the dynamic and thermal factors. Firstly, we consider the dynamic factors. Strong winds induced by PL over the sea cause vertical mixing which is sufficient to involve warm Atlantic subsurface waters from below and, therefore, to 
increase the UML surface temperature. In turn, this process leads to the transfer of additional energy from the sea to the atmosphere, thereby enhancing the cyclone. Usually, the polar low has a short lifetime of less than three days [43]. However, as already noted, the duration of the considered cyclone was about 5 days.

The SST anomalies formation dynamics is considered in more details below. We selected 4 parts in the Barents Sea where the most significant changes are observed: this is the water area near the southern coast of Svalbard, in the central part of the Barents Sea, in the region near the Novaya Zemlya western coast and in the vicinity of Kolguyev Island and Kanin Peninsula. In the first three parts SST anomalies are positive, in the last one - negative. Fig. 5, $a-c$ show the temperature-depth profiles for the storm period from 00:00 01.01.1975 to 00:00 05.05.1975, i.e., for 96 hours.

Wind currents are formed under the atmospheric cyclone effect. They lead to the divergence of sea waters at the cyclone center and to the activation of the mass redistribution mechanism. So, there is a compensatory rise (upwelling) of deep waters to the surface in the central part of the cyclone and surface water downwelling at the cyclone boundaries [44].

The cyclone under study moved slowly from the region near the southern coast of Svalbard in eastward direction towards Novaya Zemlya, its center speed was about $1 \mathrm{~m} / \mathrm{s}$, thereby causing the deep water upwelling in this area. Fig 5, $a, 5, b$ shows that in the first few days the SST increases by almost $1^{\circ} \mathrm{C}$. Such an increase in temperature occurs due to the wind upwelling.

As a result of upwelling, according to Fig $5, a, 5, b$, the penetration of warm deep Atlantic waters into the overlying layers takes place. This leads to an uneven temperature distribution in these layers and to the appearance of horizontal and vertical temperature gradients, which triggers the vertical mixing mechanism. In turn, surface storm winds transport mechanical energy to the sea, sufficient to maintain and enhance vertical turbulent mixing, which also leads to water temperature increase. Since the cyclone center with weak winds is situated closer to Svalbard, the mixing depth is shallow in this area (Fig. 5, a). At the time of the storm end on January 4-5 the thickness of the UML increases from $\sim 10$ to $\sim 25 \mathrm{~m}$ near the southern coast of Svalbard as a result of turbulent mixing.

As near the southern coast of Svalbard, vast areas of positive SST anomalies are formed at the entrance of the Barents Sea and in its central part (Fig. 4, a), as a result of the Atlantic waters upwelling and their subsequent mixing with surface waters. In the central sea part, wind speeds reach $20-25 \mathrm{~m} / \mathrm{s}$. Although the mixing is stronger here, the temperature profile formation occurs to a greater extent due to the vertical advection, which is well shown in Fig. 5, b. It is during the development of the storm on January 2-4 that the SST rises due to the strong upwelling. When the upwelling decreases and even on January 5 it changes to the downwelling, the SST begins to decrease again.

The deep Atlantic waters in the Svalbard area are warmer than the Atlantic waters in the central part of the Barents Sea (Fig. 4, b). This explains the higher maximum values of the SST anomaly here compared to the central sea part (Fig. 4, a). 

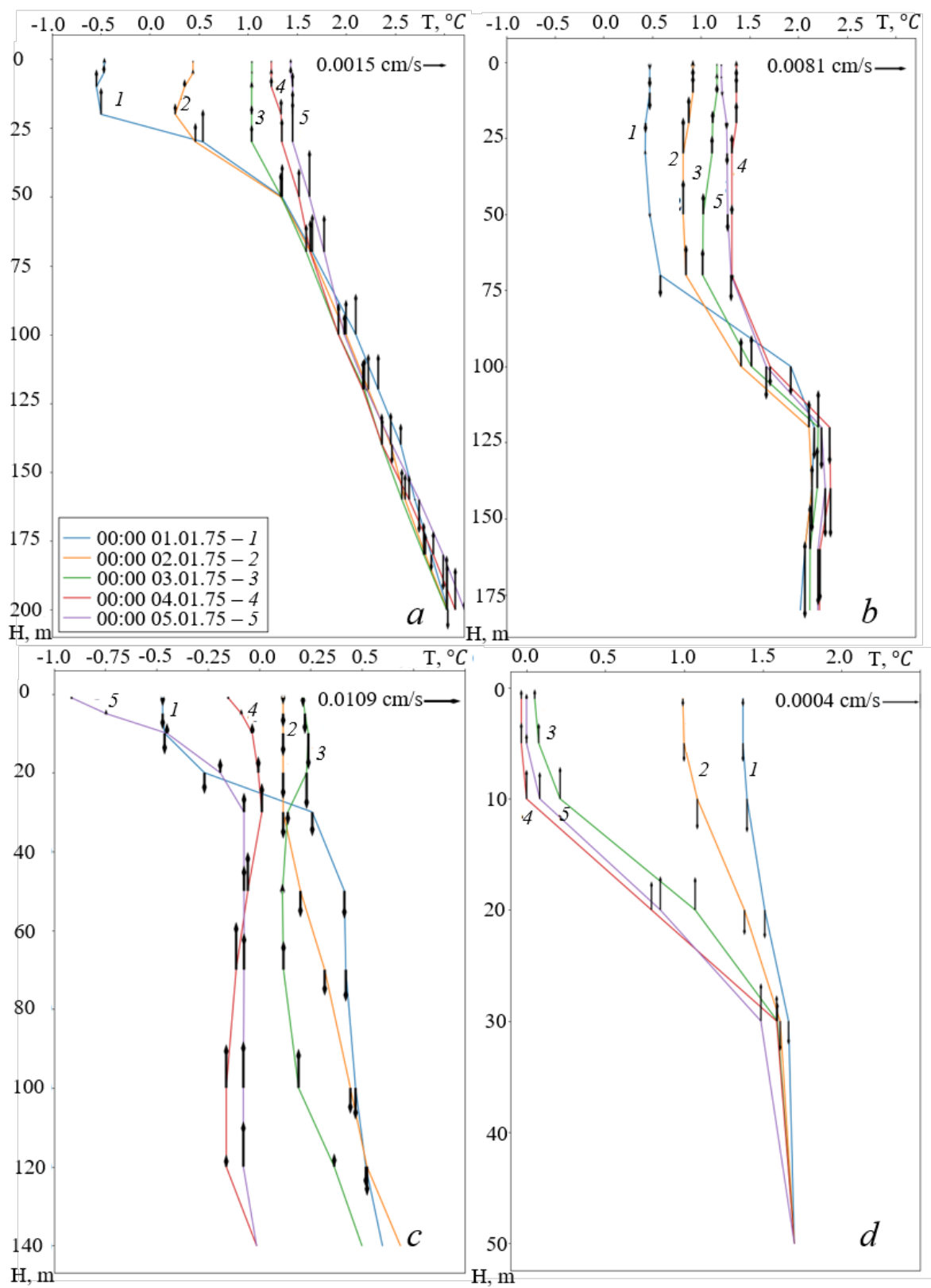

F i g. 5. Temperature profiles for the storm period (January 1-5, 1975) in the points corresponding to the main temperature anomalies in the Barents Sea (Fig. 4, a): $a$ - in point 1, b-in point 2, $c-$ in point 3 and $d-$ in point 4 . The arrows show vertical velocity $(\mathrm{cm} / \mathrm{s})$ on the scale indicated on the graphs. The profiles are numbered according to the dates

The SST increase occurs near the western coast of Novaya Zemlya, which is not typical for this area, taking into account the cold Novaya Zemlya current flowing here. Such a positive SST anomaly is associated with the storm wind, blowing almost parallel to the coast in a north and north-west direction. This leads 
to the fact that the total Ekman flow is directed toward the coast. As a result, cold surface waters are driven to the coast and sink, the so-called coastal downwelling is formed.

In place of the downwelling waters, warmer waters come from the central part of the Barents Sea. Its presence is confirmed by the observational data and calculations [42]. These processes are fully reflected in the vertical temperature profile dynamics in Fig. 5, c. Downwelling of the waters is clearly visible near the western coast of Novaya Zemlya during the storm period (profiles 1, 2, 3) as well as the restoration of the initial temperature profile of the Novaya Zemlya Current (profiles 4 and 5) with its upwelling on January 4 and 5.

In the southern part of the Barents Sea and in the Pechora Sea, a significant decrease in the surface temperature takes place, by almost $1.5^{\circ} \mathrm{C}$ (Fig. $4, a$ and $5, d$ ), as a result of the storm passing. In this relatively shallow water area, where the depths do not exceed $100 \mathrm{~m}$, the warm Coastal Murmansk Current flows. However, during the storm on January $1-3,1975$, there is the sea surface cooling due to the southern storm winds carrying cold air from the continent. Thus, in this area dynamic factors play a secondary role in the formation of the SST anomalies in comparison with the surface cooling processes shown below. According to Fig. 5, d, starting from January 3, although there is a rise in water, however, with insignificant, in comparison with other regions, vertical speeds. Therefore, upwelling cannot compensate atmospheric cooling of the sea surface here. At the same time, the UML depth is insignificant and it is about $10 \mathrm{~m}$, since the turbulent mixing is blocked by the inversion of temperature and salinity, as well as by the weak upwelling.

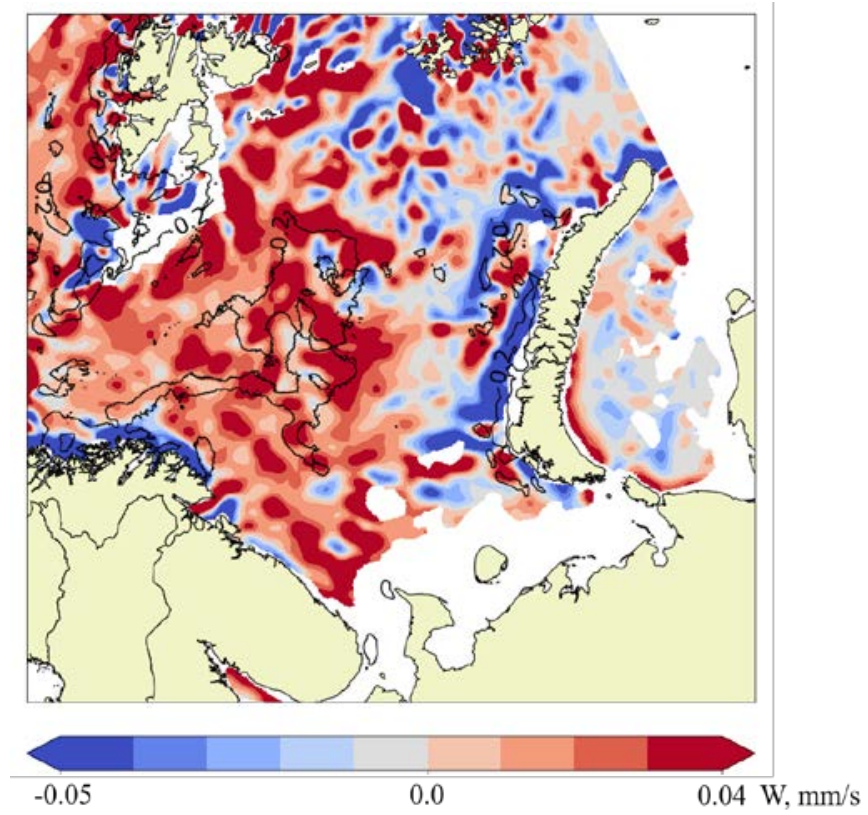

F i g. 6. Vertical velocity ( $W$, colored) at the depth $100 \mathrm{~m}$, isolines correspond to the temperature anomalies averaged for January 03, 1975 
The map of daily averaged vertical velocity at $100 \mathrm{~m}$ depth on January 3, 1975 confirms the above analysis of the SST anomalies formation due to the dynamic factors. For the area near the southern coast of Svalbard and in the central part of the Barents Sea the vertical velocity is positive in regions where positive SST anomaly is formed due to the upwelling processes (Fig. 6). Near the coast of Novaya Zemlya, on the contrary, it is negative due to the Ekman coastal downwelling, where, as shown above, a positive SST anomaly is formed due to the displacement of waters from the central part of the Barents Sea.

We consider now thermal factors, which also have impact on the formation of the SST anomalies. Intense heat transfer from the ocean to the atmosphere takes place in the Barents Sea in winter. However, the PL induces the movement of warm and humid air from the Atlantic so that the difference between the surface air temperature and the ocean surface temperature becomes positive between the southern coast of Svalbard and the northern coast of Norway (Fig. 7, a). As a result of this, as well as condensation process at the sea surface on January 2-4, 1975, the positive total heat flux is formed in these area (Fig. 7, b). In general, the total heat flux is formed by short-wave and long-wave radiation and by latent and sensible heat fluxes, which are calculated using bulk formulas [45]. In winter, there is no short-wave radiation flux. The area of positive heat flux from the atmosphere to the sea near Svalbard is formed mainly due to the sensible and latent heat fluxes (which are approximately comparable in values), as well as the long-wave radiation flux, which is 2-3 times smaller than turbulent fluxes. Intense heat transfer to the atmosphere occurs in the southern and eastern parts of the Barents Sea. It is formed during the storm on January 1-3, 1975 due to the southern storm winds that transport cold air from the continent.
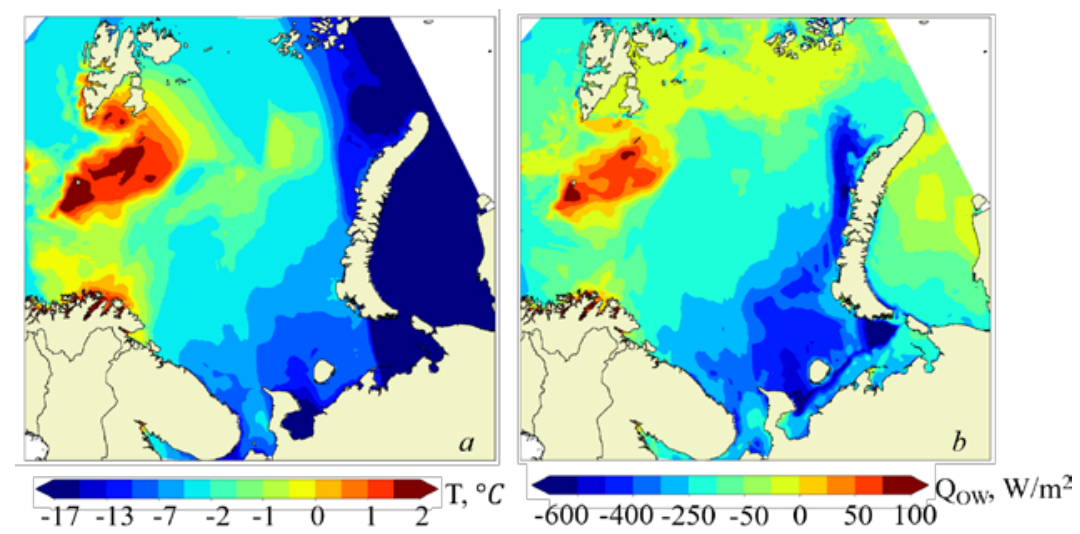

F i g. 7. Difference between the surface air temperature interpolated to the INMOM model grid and SST on January 3, $1975-a$; total heat flux on the sea surface on January 3, 1975 at 00:00 a. m. $-b$. Positive flow means that the sea receives heat, negative one means loss of heat directed from the sea surface

The positive heat fluxes in the vicinity of Svalbard are relatively small, so they have little effect on the temperature increase. Thus, it has been shown that the position of all zones with positive SST anomalies is mainly due to the dynamic factors such as turbulent mixing and advection. This is especially evident in 
the region of the Novaya Zemlya Current, where heat fluxes are negative. Negative SST anomalies are formed by heat fluxes between the atmosphere and the sea in the shallower Pechora sea.

\section{Conclusions}

Using the Marine and Atmospheric Research System implemented for the western seas of the Russian part of the Arctic, an intense polar low was reproduced. This cyclone was observed over the Barents Sea in early January 1975, and the retrospective calculation of the upper sea layer reaction to its passing was carried out. It was the strongest for the central and eastern parts of the Barents Sea, starting from the 1950s up to the present day. According to the previous estimates, the recurrence interval of a storm caused by such cyclone is approximately 400 years. It was formed on December 30, 1974 in the northwestern part of the Greenland Sea along the ice edge and, moving at a speed of approximately $7 \mathrm{~m} / \mathrm{s}$, it reached the northwestern part of the Barents Sea in less than two days, where it slowed down to $\sim 1 \mathrm{~m} / \mathrm{s}$ and remained over the sea for almost 5 days.

Considering polar low in the central and eastern parts of the Barents Sea the near-surface current velocities changed significantly, being strongly influenced by the storm winds. The structure of the daily averaged currents is almost completely determined by the drift component in these areas during the storm period. Over the extreme storm development, the contribution of the drift component is comparable and exceeds the contribution of the tidal component to the kinetic energy in the whole Barents Sea basin. Analysis of the kinetic energy density in the upper 5-meter layer near the Shtokman field shows that during the storm period the drift component contribute the most to the kinetic energy, since tidal movements are weak here. In the shallower part of the Barents Sea, near the Prirazlomnaya playform, the contribution of the tidal component to kinetic energy prevails both during storm situations and in the non-storm period. Despite the intense storm impact on the structure of the surface currents, thermohaline currents change insignificantly at the depths of $\sim 50 \mathrm{~m}$.

Frequently, a polar low lifetime is short and does not exceed three days, however, the considered cyclone lasted for 5 days. Apparently, this is due to the additional energy supply induced by positive anomalies in the sea surface temperature. It has been shown that a polar low can lead to an increase in the surface temperature by more than $1^{\circ} \mathrm{C}$ in the Barents Sea, which is not typical for the tropical cyclones. The main processes that form a positive anomaly in the sea surface temperature are dynamic factors: vertical mixing and upwelling of waters in the western and central parts of the Barents Sea and Ekman drift and downwelling along the coast of Novaya Zemlya. As a result of these processes, in the presence of temperature inversion, warmer Atlantic waters penetrate from depths of 50-100 m into the upper mixed layer. The effect of the heat exchange with the atmosphere is insignificant in the formation of positive anomalies in the sea surface temperature. The thickness of the upper mixed layer is $\sim 25 \mathrm{~m}$ compared to the initial 10 at the end of the storm on January 4-5, 1975 near the southern coast of Svalbard, as a result of turbulent mixing.

Significant decrease in the surface temperature takes place, by almost $1.5^{\circ} \mathrm{C}$, in the southern part of the Barents Sea and in the Pechora Sea in respect to the polar low 
passing. This is the result of the upper sea layer atmospheric cooling due to the negative heat fluxes from the sea surface and the southern storm winds at the polar low periphery. Moreover, the depth of the upper mixed layer is insignificant and amounts to about $10 \mathrm{~m}$, since turbulent mixing is blocked by the temperature and salinity inversion, as well as by the weak upwelling.

\section{REFERENCES}

1. Nikitin, M.A., Rivin, G.S., Rozinkina, I.A. and Chumakov, M.M., 2015. [Polar Lows Identification Under the Kara Sea Using Numerical Modelling]. Vesti Gazovoy Nayki, (2), pp. 106-112. Available at: http://www.vesti-gas.ru/sites/default/files/attachments/vgn-2-222015-106-112.pdf [Accessed: 25 July 2019] (in Russian).

2. Rasmussen, E. and Turner, J., eds. 2003. Polar Lows: Mesoscale Weather Systems in the Polar Regions. Cambridge, UK: Cambridge University Press. 612 p. doi:10.1017/CBO9780511524974

3. Rinke, A., Maturilli, M., Graham, R.M., Matthes, H., Handorf, D., Cohen, L., Hudson, S.R. and Moore, J.C., 2017. Extreme Cyclone Events in the Arctic: Wintertime Variability and Trends. Environmental Research Letters, [e-journal] 12(9), 094006. doi:10.1088/1748-9326/aa7def

4. Heinemann, G. and Saetra, Ø., 2013. Workshop on Polar Lows. Bulletin of the American Meteorological Society, [e-journal] 94(9), pp. ES123-ES126. doi:10.1175/BAMS-D-12-00190.1

5. Walker, N.D., Leben, R.R. and Balasubramanian, S., 2005. Hurricane-Forced Upwelling and Chlorophyll-a Enhancement within Cold-Core Cyclones in the Gulf of Mexico. Geophysical Research Letters, [e-journal] 32(18), L18610. doi:10.1029/2005GL023716

6. Trenberth, K.E., Cheng, L., Jacobs, P., Zhang, Y. and Fasullo, J., 2018. Hurricane Harvey links to Ocean Heat Content and Climate Change Adaptation. Earth's Future, [e-journal] 6(5), pp. 730-744. doi:10.1029/2018EF000825

7. Yang, B., Hou, Y., Hu, P., Liu, Z. and Liu, Y., 2015. Shallow Ocean Response to Tropical Cyclones Observed on the Continental Shelf of the Northwestern South China Sea. Journal of Geophysical Research: Oceans, [e-journal] 120(5), pp. 3817-3836. doi:10.1002/2015JC010783

8. Yang, B., Hou, Y. and Li, M., 2019. Response of the Western North Pacific Subtropical Ocean to the Slow-Moving Super Typhoon Nanmadol. Journal of Oceanology and Limnology, [e-journal] 37(3), pp. 938-956. doi:10.1007/s00343-019-8114-0

9. Jullien, S., Menkes, C.E., Marchesiello, P., Jourdain, N.C., Lengaigne, M., Koch-Larrouy, A., Lefèvre, J., Vincent, E.M. and Faure, V., 2012. Impact of Tropical Cyclones on the Heat Budget of the South Pacific Ocean. Journal of Physical Oceanography, [e-journal] 42(11), pp.1882-1906. doi:10.1175/JPO-D-11-0133.1

10. Pei, Y.H., Zhang, R.H. and Chen, D.K., 2008. Upper Ocean Response to Tropical Cyclone Wind Forcing: A Case Study of Typhoon Rammasun (2008). Science China Earth Sciences, [e-journal] 58(9), pp. 1623-1632. doi:10.1007/s11430-015-5127-1

11. Mathew, S., Natesan, U., Latha, G., Venkatesan, R., Rao, R.R. and Ravichandran, M., 2018. Observed Warming of Sea Surface Temperature in Response to Tropical Cyclone Thane in the Bay of Bengal. Current Science, [e-journal] 114(7), pp. 1407-1413. doi:10.18520/cs/v114/i07/1407-1413

12. Yarovaya, D.A., Efimov, V.V., Barabanov, V.S. and Mizyuk A.A., 2020. Disturbances of the Black Sea Upper Layer Caused by the Passage of the Quasi-Tropical Cyclone on September, 25-29, 2005. Russian Meteorology and Hydrology (in press).

13. Saetra, O., Linders, T. and Debernard, J.B., 2008. Can Polar Lows Lead to a Warming of the Ocean Surface? Tellus A: Dynamic Meteorology and Oceanography, [e-journal] 60(1), pp. 141-153. doi:10.1111/j.1600-0870.2007.00279.x

14. Linders, T., Saetra, Ø. and Bracegirdle, T.J., 2011. Limited Polar Low Sensitivity to Sea-Surface Temperature. Quarterly Journal of the Royal Meteorological Society, [e-journal] 137(654), pp. 58-69. doi:10.1002/qj.718 
15. Blunden, J. and Arndt, D.S., 2015. State of the Climate in 2014. Bulletin of the American Meteorological Society, [e-journal] 96(7), pp. ES1-ES32. doi:10.1175/2015BAMSStateoftheClimate.1

16. Blunden, J. and Arndt, D.S., 2016. State of the Climate in 2015. Bulletin of the American Meteorological Society, [e-journal] 97(8), pp. S1-S275. doi:10.1175/2016BAMSStateoftheClimate.1

17. Hausfather, Z., Cowtan, K., Clarke, D.C., Jacobs, P., Richardson, M. and Rohde, R., 2017. Assessing Recent Warming Using Instrumentally Homogeneous Sea Surface Temperature Records. Science Advances, [e-journal] 3(1), e1601207. doi:10.1126/sciadv.1601207

18. Zahn, M. and von Storch, H., 2008. A long-Term Climatology of North Atlantic Polar Lows. Geophysical Research Letters, [e-journal] 35(22), L22702. doi:10.1029/2008GL035769

19. Zahn, M. and von Storch, H., 2010. Decreased Frequency of North Atlantic Polar Lows Associated with Future Climate Warming. Nature, [e-journal] 467(7313), pp. 309-312. doi:10.1038/nature09388

20. Diansky, N.A., Kabatchenko, I.M., Fomin, V.V., Panasenkova, I.I. and Reznikov, M.V., 2018. A Marine and Atmospheric Research System for Simulating Hydrometeorological Characteristics and Wing Waves in the Western Seas of Russian Arctic, and Simulation of the Extreme Storm of 1975 in Barents Sea with Ice Conditions. Vesti Gazovoy Nauki, (4), pp. 156-165. Available at: http://vesti-gas.ru/sites/default/files/attachments/vgn-4-36-2018156-165.pdf [Accessed: 25 July 2019] (in Russian).

21. Vasil'ev, K.P. ed., 1982. [A Collection of Maps and Descriptions of Typical Atmospheric Processes Causing the Occurrence of Dangerous and Extremely Dangerous Hydrometeorological Phenomena in the Barents, the Norwegian and Greenland Seas]. Moscow: VNIIGMI-MTsD, 136 p. (in Russian).

22. Gusev, A.V. and Diansky, N.A., 2014. Numerical Simulation of the World Ocean Circulation and Its Climatic Variability for 1948-2007 Using the INMOM. Izvestiya, Atmospheric and Oceanic Physics, [e-journal] 50(1), pp. 1-12. doi:10.1134/S0001433813060078

23. Popov, S.K. and Lobov, A.L., 2017. Diagnosis and Forecast of the Caspian Sea Level with the Operational Hydrodynamic Model. Russian Meteorology and Hydrology, [e-journal] 42(9), pp. 607-614. doi:10.3103/S1068373917090084

24. Popov, S.K., Lobov, A.L., Elisov, V.V. and Batov V.I., 2013. A Tide in the Operational Model for Short-Range Forecast of Current Velocity and Sea Level in the Barents and White Seas. Russian Meteorology and Hydrology, [e-journal] 38(6), pp. 414-425. doi:10.3103/S106837391306006X

25. Nikitin, M.A., Rivin, G.S., Rozinkina, I.A. and Chumakov, M.M., 2016. Use of COSMO-Ru Forecasting System for Polar Low's Research: Case Study 25-27 March 2014. In: V. V. Ivanov, 2016. Proceedings of Hydrometcentre of Russia. Moscow, Hydrometcentre of Russia. Issue 361, pp. 128-145 (in Russian).

26. Mironov, Ye.U., Smirnov, V.G., Bychkova, I.A., Kulakov, M.Yu. and Demchev, D.M., 2015. Modern Technologies for Iceberg Detection and Their Drift Forecasting in the Western Arctic. Arctic and Antarctic Research, (2), pp. 21-32. Available at: http://www.aari.ru/misc/publicat/paa/PAA-104/PAA-104_021-032.pdf [Accessed: 25 July 2019] (in Russian).

27. Kulakov, M.Yu., Makshtas, A.P. and Shutilin, S.V., 2012. AARI-IOCM - Coupled IceOcean Circulation Model for the Arctic Ocean. Arctic and Antarctic Research, (2), pp. 6-18 (in Russian).

28. Sakov, P., Counillon, F., Bertino, L., Lisæter, K.A., Oke, P.R. and Korablev, A., 2012. TOPAZ4: an Ocean-Sea Ice Data Assimilation System for the North Atlantic and Arctic. Ocean Science, [e-journal] 8(4), pp. 633-656. https://doi.org/10.5194/os-8-633-2012

29. Skamarock, W.C., Klemp, J.B., Dudhia, J., Gill, D.O., Barker, D.M., Duda, M.G., Huang, X.-Yu, Wang, W. and Powers, J.G., 2008. A Description of the Advanced Research WRF Version 3. NCAR Technical Notes. Boulder, Colorado: National Center for Atmospheric Research USA, 113 p. Available at: https://opensky.ucar.edu/islandora/object/technotes\%3A500/datastream/PDF/view 
[Accessed: 25 July 2019].

30. Diansky, N.A., 2013. [Modeling the Ocean Circulation and Study of Its Response to Shortand Long-Period Atmospheric Influences]. Moscow: Fizmatlit, $272 \mathrm{p}$.

31. Moshonkin, S., Zalesny, V. and Gusev, A., 2018. Simulation of the Arctic-North Atlantic Ocean Circulation with a Two-Equation K-Omega Turbulence Parameterization. Journal of Marine Science and Engineering, [e-journal] 6(3), 95. doi:10.3390/jmse6030095

32. Zalesnyi, V.B., 1998. Numerical Modeling of the World Ocean Thermohaline Circulation. Russian Meteorology and Hydrology, (2), p. 32-40.

33. Kabatchenko, I.M., Matushevskii, G.V., Reznikov, M.V. and Zaslavskii, M.M., 2001. Numerical Modelling of Wind and Waves in a Secondary Cyclone at the Black Sea. Russian Meteorology and Hydrology, (5), p. 45-53.

34. Efimov, V.V. and Komarovskaya, O.I., 2017. Formation of the Novaya Zemlya Bora. Physical Oceanography, [e-journal] (2), pp. 3-10. doi:10.22449/1573-160X-2017-2-3-10

35. Gruzinov, V.M., Diansky, N.A., Kabatchenko, I.M. and Fomin, V.V., 2014. Simulation of Circulation of the Kara and Pechora Seas through the System of Express Diagnosis and Prognosis of Marine Dynamics. Arctic: Ecology and Economy, 1(13), pp. 57-73 (in Russian).

36. Locarnini, R.A., Mishonov, A.V., Antonov, J.I., Boyer, T.P., Garcia, H.E., Baranova, O.K., Zweng, M.M., Paver, C.R., Reagan, J.R., Johnson, D.R., Hamilton, M. and Seidov, D., 2013. World Ocean Atlas 2013, Volume 1: Temperature. NOAA Atlas NESDIS 73. Silver Spring, MD: NODC, 40 p. doi:10.7289/V55X26VD

37. Papritz, L. and Spengler, T., 2017. A Lagrangian Climatology of Wintertime Cold Air Outbreaks in the Irminger and Nordic Seas and Their Role in Shaping Air-Sea Heat Fluxes. Journal of Climate, [e-journal] 30(8), pp. 2717-2737. doi:10.1175/JCLI-D-16-0605.1

38. Carscadden, J.E., Gjøsæter, H. and Vilhjálmsson, H., 2013. A Comparison of Recent Changes in Distribution of Capelin (Mallotus Villosus) in the Barents Sea, around Iceland and in the Northwest Atlantic. Progress in Oceanography, [e-journal] 114, pp. 64-83. doi:10.1016/j.pocean.2013.05.005

39. Terziev, F.S., Girdyuk, G.V., Zukova, G.G. and Dzhenyuk, S.L., eds., 1990. [Hydrometeorology and Hydrochemistry of the Seas of the USSR. Vol. 1: Barents Sea. No. 1: Hydrometeorological Conditions]. Leningrad: Gidrometeoizdat, 280 p. (in Russian).

40. Price, J.F., 1981. Upper Ocean Response to a Hurricane. Journal of Physical Oceanography, [e-journal] 11(2), pp. 153-175. doi:10.1175/1520-0485(1981)011<0153:UORTAH>2.0.CO;2

41. Schauer, U., Loeng, H., Rudels, B., Ozhigin, V.K. and Dieck, W., 2002. Atlantic Water Flow through the Barents and Kara Seas. Deep-Sea Research Part I: Oceanographic Research Papers, [e-journal] 49(12), pp. 2281-2298. doi:10.1016/S0967-0637(02)00125-5

42. Makhotin, M.S., and Ivanov, V.V., 2016. Circulation of the Atlantic Water in the Barents Sea Based on Hydrological Survey Data and Numerical Simulation. In: V. V. Ivanov, 2016. Proceedings of Hydrometcentre of Russia. Moscow: Hydrometcentre of Russia. Issue 361, pp. 169-191 (in Russian).

43. Nesterov, E.S, 2018. Extreme Cyclones over the Seas of the European Part of Russia. Hydrometeorological Research and Forecasting, 1(367). C. 97-115. Available at: http://method.meteorf.ru/publ/tr/tr367/05.pdf [Accessed: 25 July 2019].

44. Jaimes, B. and Shay, L.K., 2015. Enhanced Wind-Driven Downwelling Flow in Warm Oceanic Eddy Features during the Intensification of Tropical Cyclone Isaac (2012): Observations and Theory. Journal of Physical Oceanography, [e-journal] 45(6), pp. 1667-1689. doi:10.1175/JPO-D-14-0176.1

45. Gill, A.E., 1982. Atmosphere-Ocean Dynamics. International Geophysics Series, vol. 30. London: Academic Press, 662 p.

About the authors:

Nikolay A. Diansky - Leading Research Associate, Lomonosov Moscow State University (1-2 Leninskie Gory, Moscow, 119991, Russian Federation), Dr. Sci (Phys.-Math.), Associate professor, ORCID ID: 0000-0002-6785-1956, ResearcherID: R-8307-2018, nikolay.diansky@gmail.com 
Irina I. Panasenkova - Junior Research Associate, N.N. Zubov State Oceanographic Institute (6 Kropotkinsky Lane, Moscow, 119034, Russian Federation), ORCID ID: 0000-0002-8338-4825, ResearcherID: AAE-4131-2019, ipanasenkova@mail.ru

Vladimir V. Fomin - Senior Research Associate, N.N. Zubov State Oceanographic Institute (6 Kropotkinsky Lane, Moscow, 119034, Russian Federation), ORCID ID: 0000-0001-8857-1518, ResearcherID: C-2124-2017, vladimirfomin@live.com

Contribution of the authors:

Nikolay A. Diansky - formulation of the research problem; consulting support; discussion of the work results; critical analysis and revision of the text

Irina I. Panasenkova - carrying out numerical experiments; analysis of the research results; preparation of the text and graphic materials

Vladimir V. Fomin - assistance in carrying out numerical experiments; discussion of the work results; editing and supplementation of the article text

All the authors have read and approved the final manuscript.

The authors declare that they have no conflict of interest. 